\title{
GUIIA DE PRÁCTICA CLÍNICA PARA DIAGNÓSTICO Y MANEJO DE LA TOXOPLASMOSIS GESTACIONAL
}

\author{
PRACTICE GUIIDELINE FOR DIAGNOSIS AND \\ MANAGEMENT OF GESTATIONAL TOXOPLASMOSIS
}

Carlos A. Olaya Urueña, M.D. ", Diego F. Flórez García, M.D. **

Recibido: marzo 27/2003 - Revisado: mayo 13/2003 - Aceptado: junio 13/2003

\section{RESUMEN}

Objetivo: obtener una guía para diagnóstico y manejo de la toxoplasmosis gestacional, actualizada, científicamente confiable, práctica, aplicable a Latinoamérica y que permita influir positivamente en la salud obstétrica.

Materiales y metodos: se realizó una revisión de artículos elaborados en los últimos 10 años relacionados con la toxoplasmosis en el embarazo, publicados en Medline, Pub-Med, Cochrane Review y literatura científica nacional. Luego de selecionar esta información se recopilaron los más importantes y se procedió a elaborar una guía de diagnóstico y manejo de la toxoplasmosis gestacional.

Resultados: A partir de la interpretación de las curvas de comportamiento de la IgG e IgM específicas para Toxoplasma gondii, fue posible integrar una conducta médica adecuada con un determinado resultado serológico, para reducir al máximo la incorrecta interpretación de los paraclínicos, que se constituyen actualmente en la única herramienta para la detección de una enfermedad en gran parte subclínica.

MD. Ginecólogo y Obstetra, Universidad Nacional de Colombia, Hospital Federico Lleras, ISS. Ibagué, Tolima

** MD. Interno, Universidad del Tolima, ISS. Ibagué, Tolima. Hospital Regional. Líbano, Tolima.
Conclusion: La información obtenida es reciente y con un irrefutable valor científico que permitirá abordar con más claridad esta patología, además al realizar una guía de diagnóstico y manejo será posible restarle complejidad a la interpretación de las pruebas serológicas destinadas a su detección.

Palabras clave: toxoplasmosis aguda y crónica, Inmunoglobulinas G, M, A y E, PCR, ELISA, quimioluminiscencia.

\section{SUMMARY}

Objective: To obtain a guide for diagnostic and treatment of the toxoplasmosis in the pregnancy, up-to-date, scientifically reliable, practice, applicable to Latin America and that it allows to influence positively in the obstetric health.

Materials and methods: It was carried out a search of articles elaborated in the last 10 years, related to toxoplasmosis during the pregnancy, published in Medline, Pub-Med, Cochrane Review and national scientific literature. After sifting this information were gathered and separate the most important and then we proceeded to elaborate a guide of diagnostic and treatment of toxoplasmosis in the pregnancy. 
Outcome: Starting from the interpretation of the curves of behavior of the IgG and specific IgM for Toxoplasma gondii, it was possible to integrate an appropriate medical behavior to a certain serologic, foreseeing to reduce to the maximum the incorrect interpretation of the paraclinics, actually the only tool for the detection of an subclinic illness.

Conclusion: The information obtained is recent and with an irrefutable scientific value, and will allow a more reliable approach of this pathology. Also, carrying out a guide of diagnostic and treatment will be possible to subtract him complexity to the interpretation of the serologic tests for its detection.

Key words: Acute and chronic toxoplasmosis, Inmunoglobulins G, M, A and E, PCR, ELISA, quimioluminiscency.

\section{INTRODUCCIÓN}

El Toxoplasma gondii es un protozoario de la subclase Coccidiae (igualmente lo son Isospora y Cryptosporidium), que se comporta como parásito intracelular obligado y cuyos huéspedes definitivos son los felinos, siendo los humanos huéspedes intermedios, al igual que los mamíferos cuadrúpedos y un grupo variado de aves. Los felinos lo alojan en la mucosa intestinal y expulsan a través de sus heces 10 millones de ooquistes diariamente. Cada ooquiste está compuesto por ocho esporozoitos, que son la verdadera forma parasitaria infectante y que se libera al contacto con el suelo. Cabe anotar que el ooquiste podrá permanecer viable fuera del hospedero hasta por 18 semanas, si las condiciones de humedad y temperatura son favorables.

Desde la tierra el Toxoplasma gondii se disemina a una gran cantidad de hospederos intermediarios incluyendo al humano, a quien infecta directa o indirectamente. En el humano inmunocompetente este parásito permanece latente en el músculo esquelético e incluso puede ser eliminado por completo sin ocasionar mayores manifestaciones clínicas. Además genera una memoria inmunológica que lo protege de futuras infecciones.

Lo contrario ocurre en el paciente inmunodeficiente o en el feto, en quienes ocasiona importantes trastornos. La severidad de las lesiones fetales son inversamente proporcionales a la edad gestacional en la que el feto adquiere la infección, mientras que la transmisión materno-fetal del parásito es directamente proporcional a la edad gestacional (tabla 1).

\section{EPIDEMIOLOGÍA Y PREVENCIÓN}

Se calcula que en Colombia entre 2 y 10 de cada mil nacidos vivos sufren de toxoplasmosis congénita. Por tanto, anualmente nacen más de 3000 niños con la enfermedad, de los cuales $85-90 \%$ son asintomáticos. Por otro lado, 47\% de la población femenina colombiana posee anticuerpos contra $T$. gondii. (Estudio Nacional de Salud- MSN, Bogotá 1983), lo cual demuestra la alta prevalencia en nuestro medio. Uno de los estudios más importantes sobre toxoplasmosis congénita en Latinoamérica fue realizado en el departamento del Quindío (Colombia), que informó una frecuencia de seroconversión en maternas de 1.9\% (IC 95\%: 1.2-2.8\%). ${ }^{2}$

El programa nacional para la prevención de toxoplasmosis en el embarazo en Bélgica reporta en 1998 una reducción del 63\% en la frecuencia de seroconversión en mujeres grávidas, tan solo con la promoción de hábitos higiénicos específicos para

Tabla 1. Riesgo de infección fetal según la edad gestacional en inmunocompetentes. ${ }^{1}$

\begin{tabular}{lcc} 
Trimestre & Semana & $\begin{array}{c}\text { Riesgo de } \\
\text { infección fetal }\end{array}$ \\
\hline PRIMERO & $0-10$ & $2 \%$ \\
& $11-15$ & $15-20 \%$ \\
\hline SEGUNDO & $16-28$ & $30-55 \%$ \\
\hline TERCERO & $29-42$ & $60-65 \%$ \\
\hline
\end{tabular}


evitar la enfermedad. VAle la pena resaltar que en Europa la principal fuente de contagio es el consumo de carnes mal cocidas.

A toda mujer gestante seronegativa se le debe informar sobre la importancia que tiene el lavado de las manos después de tener contacto con tierra, animales, carne cruda o personas que han tenido contacto con lo anteriormente descrito. Igualmente debe asistir a controles de serología específica para $T$. gondii cada tres meses. ${ }^{4} \mathrm{La}$ cocción de las carnes debe ser completa, y no debe quedar cruda o mal cocida porque favorece la sobrevida de quistes tisulares o trofozoitos, los cuales desaparecen sólo a temperaturas mayores de $61^{\circ} \mathrm{C}$. Así mismo, las verduras, frutas y otros vegetales requieren de un buen lavado. Por último, la leche y los huevos necesitan cocinarse a temperaturas elevadas de cocción.

Cuando se ofrece manejo farmacológico temprano a la gestante con toxoplasmosis aguda, puede lograrse hasta un $83 \%$ de recién nacidos libres de enfermedad. El 17\% restante tiene un curso variable: el 67\% no tendrá ninguna actividad clínica como secuela de la enfermedad, mientras el $37 \%$ de las toxoplasmosis congénitas tratadas in utero, presentarán uno o más signos clínicos pero sin manifestaciones neurológicas, hecho evaluado en estudios de seguimiento durante los primeros 5 años de vida. (Hospital La Grave. Toulousse, Francia) ${ }^{15}$ (tabla 2).

\section{CONSIDERACIONES}

Una prueba serológica positiva IgG e IgM específica para T. gondii (con ELISA, IFI, Quimioluminiscencia, etc.) indica la presencia del anticuerpo, pero es insuficiente para establecer el tiempo en que ocurrió la in- fección. Este último dato se infiere al correlacionar la variación en los títulos séricos de IgG y la IgM, según se describe en la literatura (figura 1).

De todas maneras es importante considerar el margen de error que tienen estas pruebas. En el caso de la IgM pueden aparecer valores muy bajos y algunas veces indetectables cuando hay una cepa poco virulenta, ocurre un efecto prozona o la persona se encuentra inmunodeprimida. En tales circunstancias, podría interpretarse el examen como una infección antigua o inexistente cuando en realidad de está en presencia de una infección aguda.

Por ello en la actualidad existen pruebas que confirman la sospecha diagnóstica y ayudan a determinar qué tan aguda es la infección. Entre ellas se destacan la prueba de afinidad de la IgG, detección de la IgA e IgE específica para $T$. gondii y la reacción de polimerasa en cadena (PCR), esta última utilizada principalmente para diagnóstico de infección fetal. Por desgracia, todas son de difícil acceso en nuestro medio. ${ }^{3}$

En estos casos la FDA recomienda no tomar decisiones apoyadas en un solo resultado. Además el seguimiento serológico debe ser siempre con una misma técnica de medición (figura 2).

\begin{tabular}{|c|c|}
\hline Primer trimestre & Segundo y tercer trimestre \\
\hline $\begin{array}{l}\text { Aborto espontáneo - } 90 \% \\
\text { - Signos de infección severa (10\%), } \\
\text { principalmente la triada clásica } \\
\text { (Calcificaciones intracerebrales, } \\
\text { hidrocefalia, retinocoroiditis); } \\
\text { también retardo mental severo y/ } \\
\text { o ceguera, miocarditis, microo- } \\
\text { ftalmia, mortinatos, etc. }\end{array}$ & $\begin{array}{l}\text { - } \text { Retinocoroiditis - } 85 \text { a } 90 \% \\
\text { - } \text { este periodo. } \\
\text { - Calcificaciones intracerebrales. } \\
\text { - Mastoiditis e infección del oído inter- } \\
\text { no (generan hipoacusia o sordera) } \\
\text { - Retardo mental leve a moderado } \\
\text { (raras veces severo) } \\
\text { - Infección de septos alveolares, sep- } \\
\text { tum interventricular y ventrículo } \\
\text { derecho cardiaco; glomerulone- } \\
\text { fritis focal, restricción del creci- } \\
\text { miento intrauterino. }\end{array}$ \\
\hline
\end{tabular}




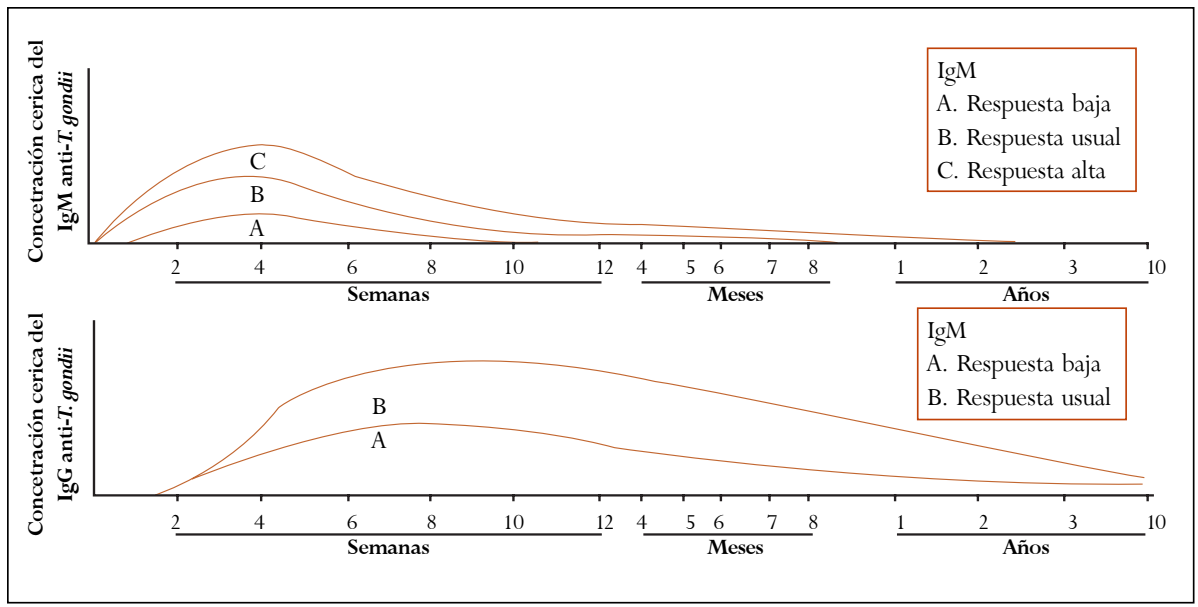

Figura 1: Curvas de comportamiento de $\operatorname{IgG}$ e $\operatorname{IgM}$ específica para T. gondii (Olaya Urueña C., Flórez García D.)

- En la interpretación de resultados de IgG e IgM puede ocurrir un «efecto prozona», el cual consiste en que grandes cantidades de IgG hacen que un sistema electrónico reporte como negativa la IgM en una infección aguda (haciendo suponer que es una infección antigua). Bajo tales circunstancias es necesario repetir la medición de IgG e IgM en 15 días o realizar otras técnicas de detección de infección aguda. Esta situación se presenta en el 20\% de todas las infecciones agudas por T. gondii (tabla 3).

- Es importante realizar controles frecuentes con ecografía obstétrica a mujeres embarazadas con diagnóstico de toxoplasmosis aguda, pues al encontrar signos fetales asociados a esta infección se mejora notablemente la sensibilidad del diagnóstico. El tiempo requerido entre una y otra ecografía queda a criterio médico porque no existe consenso al respecto.

- El tiempo recomendado en la mayoría de referencias consultadas para repetir una prueba serológica de $\operatorname{IgG}$ e IgM específica para T. gondii en caso de diagnóstico no claro,es de 15 días. Lo anterior obedece más a la experiencia de los laboratorios de referencia y a la urgencia médica de tomar una conducta que beneficie a la madre y a su hijo.

- Idealmente a toda mujer en edad fértil debería realizárse una serología IgG específica para T. gondii preconcepcional, lo cual permite abordar de manera más eficiente dicha problemática. Por lo demás, no existe duda de que los beneficios superan los costos. ${ }^{1,3}$

- El feto no es capaz de sintetizar ninguna inmunoglobulina, pero en el tercer trimestre del embarazo pasan de la madre al feto cantidades apreciables de $\operatorname{IgG}$ mediante transporte activo transtrofoblástico, convirtiéndose la IgG en el

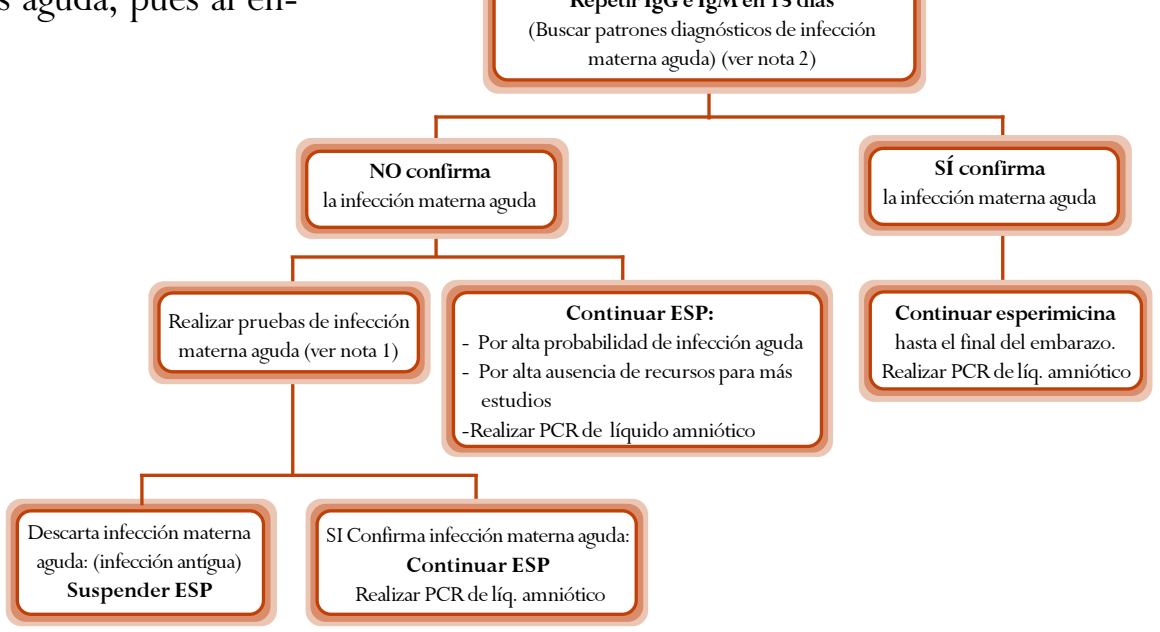

Figura 2: Conducta a seguir a partir de los reportes serológicos de IgG e IgM IgM para T. gondii en el embarazo (Olaya Urueña C. , Flórez García D.) 
único anticuerpo que puede atravesar la placenta; en el neonato la IgM se produce inmediatamente nace, la IgA a las tres semanas de nacido y la IgG a las seis semanas.

- Actualmente el Toxoplasma gondii puede agruparse en tres subespecies, la TG-1 o altamente virulenta, la TG-2 o moderadamente virulenta y la TG-3 o levemente virulenta. Todavía no existen estudios sobre el comportamiento de cada subespecie en humanos, pero estos patrones son previsibles mediante técnicas de laboratorio. ${ }^{6,7}$

No existe un consenso que establezca criterios definidos para interrupción del embarazo en la toxoplasmosis materno fetal, pero los trastornos

Tabla 3. Guía de práctica clínica para diagnóstico y manejo de la toxoplasmosis gestacional (Olaya Urueña C. , Flórez García D.)

\begin{tabular}{|c|c|c|c|}
\hline \multicolumn{4}{|c|}{ Resultado } \\
\hline IgG & IgM & & Conducta \\
\hline$\ominus$ & $\ominus$ & $\rightarrow$ & $\begin{array}{l}\text { - Prevención y seguimiento cada tres meses con } \operatorname{IgG} \text { hasta finalizar el embarazo } \\
\text { (Prioritario por alta prevalencia de toxoplasmosis: costo-beneficio) }\end{array}$ \\
\hline$\oplus$ & $\ominus$ & $\rightarrow$ & $\begin{array}{l}\text { - Actualmente la elevada sensibilidad y especificidad de las técnicas serológicas indican que } \\
\text { esto es una infección antigua, pero debe decartarse siempre: } \\
\text { - Efecto Prozona ( } 20 \% \text { de los casos positivos, cifras de } \operatorname{IgG} \text { muy altas e IgM negativa ) } \\
\text { - Infección aguda con cepas de baja virulencia que generan una respuesta escasa de la } \\
\text { IgM, algunas veces indetectable (falso negativo). } \\
\text { - En estos casos se recomienda repetir IgG e IgM en } 15 \text { días, si continúa ausente la IgM } \\
\text { no tratar ni hacer seguimiento pues se trata de una infección antigua, pero si hay } \\
\text { patrones diagnósticos serológicos de infección aguda (Ver Nota 2) o diagnóstico dudoso } \\
\text { debe iniciarse tratamiento y evaluar la posibilidad de realizar alguna de las pruebas de } \\
\text { infección aguda. (Ver Nota 1) }\end{array}$ \\
\hline$\ominus$ & $\oplus$ & $\rightarrow$ & $\begin{array}{l}\text { - Iniciar ESP lo más pronto posible y repetir inmediatamente IgG e IgM en } 15 \text { días para } \\
\text { confirmar el diagnóstico (Ver Nota 2), pero si continúa positiva la IgM en ausencia de la } \\
\text { IgG también se confirma la infección aguda. Puede ayudarse de alguna de las pruebas de } \\
\text { infección materna aguda si el diagnóstico es confuso. (Ver Nota 1). } \\
\text { - Realizar PCR de líquido amniótico para descartar infección fetal. } \\
\text { * En embarazos de } 11 \text { semanas o más, el tratamiento con ESP deberá iniciarse } \\
\text { «inmediatamente debido al alto riesgo de infección fetal». }\end{array}$ \\
\hline$\oplus$ & $\oplus$ & $\rightarrow$ & $\begin{array}{l}\text { - Iniciar ESP cuanto antes y repetir IgG e IgM en } 15 \text { días, si no hay patrones diagnósticos de } \\
\text { infección aguda con IgG e IgM (Ver Nota 2) se recomienda especialmente en estas pacientes } \\
\text { realizar pruebas más certeras (Ver Nota 1). La única justificación para suspender la ESP } \\
\text { es demostrar que no hay infección aguda en la gestante mediante pruebas de infección } \\
\text { aguda materna, de lo contrario debe continuarse con la ESP hasta el final de la gestación } \\
\text { (Ver Nota 1). } \\
\text { - Realizar PCR de líquido amniótico para descartar infección fetal. } \\
\text { * En embarazos de } 11 \text { semanas o más el tratamiento con ESP deberá iniciarse «inmediatamente } \\
\text { debido al alto riesgo de infección fetal». }\end{array}$ \\
\hline
\end{tabular}

ESP: Espiramicina

* NOTA 1: Pruebas de infección aguda : 1. PCR de cualquier fluido materno o fetal (liquido amniótico en embarazos de más de 18 sem.); 2. afinidad de la IgG; 3. IgA; 4. IgE.; 5. Visualización del parásito en microscópio de luz; 6. Inoculación en ratón. $\rightarrow$ Realizar estas pruebas en ausencia de tratamiento implica resultados en un tiempo máximo de 4 semanas, pues urge tomar una conducta para evitar o disminuir la transmisión materno-fetal del toxoplasma.

* NOTA 2: Patrones diagnósticos de infección aguda materna con IgG e IgM : 1. Seronegativa que seroconvierte, 2. IgG o IgM que aumenta , 3. $\operatorname{IgG}+\operatorname{IgM}$ que aumenta. 
fetales severos o incompatibles con la vida son considerados razones suficientes en Estados Unidos y Europa para tomar esta conducta.

\section{ESQUEMAS DE TRATAMIENTO}

\section{A. Toxoplasmosis materna :}

1. Espiramicina (ESP) x 3 millones de UI cada 8 horas $\mathrm{VO}$ (vía oral) hasta finalizar el embarazo desde cualquier semana de edad gestacional. ${ }^{1,2}$

\section{B. Toxoplasmosis fetal :}

1. Ciclos de espiramicina (ESP) x 3 mill. UI c/8 horas vía oral (VO) por tres semanas, luego suspender y administrar una vez a la semana por dos semanas sulfadoxina $500 \mathrm{mg}+$ pirimetamina $25 \mathrm{mg} \mathrm{VO}$ tres veces / día y 10 gr de levadura de pan o cerveza (como ácido folínico) VO el mismo día. Al finalizar este ciclo de dos semanas deberá realizarse un cuadro hemático (por el riesgo de anemia megaloblástica asociado a la pirimetamina, pero prevenible con la administración conjunta de ácido folínico) y luego reiniciar el ciclo con ESP y posteriormente el de pirimetamina-sulfadoxina-levadura , así hasta el final del embarazo y siempre desde la semana $20 .^{2}$

2. Sulfadoxina $500 \mathrm{mg}+$ pirimetamina $25 \mathrm{mg}$ VO. tres veces al día y 10 gr de levadura diarios VO (pan o cerveza). Esta combinación cada cuatro días desde la semana 20 hasta finalizar el embarazo. Hemograma semanal. ${ }^{2}$

3. Pirimetamina tab. x $25 \mathrm{mg}, 2$ tab. VO cada 12 horas los dos primeros días y continuar con 1 tab. c/12 horas (no usar en el primer trimestre) + sulfadiazina tab. x $500 \mathrm{mg}, 50-100 \mathrm{mg} /$ $\mathrm{Kg} /$ día VO dividido en 2 dosis + ácido folínico tab. x 5mg 10-20 mg/día VO. Este esquema se administra hasta el final del embarazo , además debe realizarse un cuadro hemático cada 15 días. $^{1}$

\section{CONCLUSIONES}

- Los diagnósticos de infección materna aguda al final del embarazo implican tratamiento con espiramicina, pero no es urgente la detección de infección fetal porque se hace prioritario el diagnóstico postnatal para realizar tratamiento del recién nacido.

- En ocasiones la IgG e IgM epecífica para T. gondii en infección materna aguda, se presentan con cifras bajas lo cual depende de: (1) la capacidad de respuesta inmune de cada paciente, (2) de la cepa del Toxoplasma gondii, (3) de la forma parasitaria que ingrese, (4) de la cantidad de parásitos que ingresen.

- «Tratar un falso positivo de toxoplasmosis materna aguda no implica mayores riesgos materno-fetales si se administra un esquema farmacológico adecuado y con estricta supervisión médica, pero no tratar una toxoplasmosis activa es una catástrofe».

\section{REFERENCIAS}

1. Agudelo A., Montoya J. Toxoplasmosis gestacional. Infecciones Propias de la Mujer. $1^{\text {a }}$ Edición Editorial Feriva. Cali-Colombia: 2001.

2. Gómez Marín J., Montoya de Londoño M. A maternal screening program for congenital toxoplasmosis in Quindio-Colombia and application of mathematical models to estimate incidences using age-stratified data. Am 3 Trop Med Hyg. Colombia: 1997: 5:180186.

3. Picazo J., Ortíz de Urbina A.F. Toxoplasma gondii. $1^{\text {a }}$ versión. INNOGENETICS LABS. E.U.:1998: www.fei.es/protocol/sero06.htm.

4. Peyron F. Treatments for toxoplasmosis in pregnancy. Cochrane Review. The Cochrane Library, íssue 3. 2000: Oxford: Update Software.

5. Muñoz C., Izquierdo C. Recommendation for prenatal screening for congenital toxoplasmosis. Eur J Clin Microbiol Infect Dis. 2000: 19 - 324 - 325.

6. Boothroyd J., Grigg M. Population biology of Toxoplasma gondii and its relevance to human 
infection: do different strains cause different disease?. Stanford University School of Medicine. California, USA: 2002: Pub Med.

7. Su C., Howe D.K., Dubey J.P., Ajioka J.W., Sibley L. Identification of quantitative trait loci controlling acute virulence in Toxoplasma gondii. Washington University School of Medicine. St. Louis, MO 63110. USA: 2002: Pub Med.

8. Dunn D., WalIn Ni. Mother to child transmission of toxoplasmosis. Risk estimates for clinical counselling. The Lancet: 1999: 353 (May):1829 - 1833

9. Lappalainen N. Cost-benefit analysis of screening for toxoplasmosis during pregnancy. Scandinavian Journal of Infectious Diseases: 1995: 27(3): 265 272
10. Remington J.S., Desmonts G. Toxoplasmosis, infeccious diseases of the fetus arid newborn infant. Fourth edition. Philadelphia. W.B Saunders: 1998: $140-267$

11. Gibbs I.R., Sweet R. Clinical disorders: Toxoplasmosis in creasy and resnick maternal -fetal medicine. Principles and practice. Philadelphia: 1994: 690 $-691$

12. Guerina N., Hsu F.I. Neonatal serologic screening aria early treatment for congenital Toxoplasma gondii infection. N Eng J Med: 1994:330(1): 555,1853

13. Burlington B. Limitations of toxoplasma IgM commercial test kíts. EDA public health advisory. (july 25) 1997: www.fda.gov/cdrh/toxopha/html

14. Botero D., Restrepo M. Parasitosis Humanas. CIB. $3^{\mathrm{a}}$ edición. Medellín-Col.

Desmonts C., Couver S. Toxoplasmosis and the pregnancy. JAMA: (enero 4) 1995: 273:35-40 